Research Article

\title{
Effect of Silane Treatment Methods on Physical Properties of Rice Husk Flour/Natural Rubber Composites
}

\author{
Ladawan Srisuwan, Kasama Jarukumjorn, and Nitinat Suppakarn \\ School of Polymer Engineering, Institute of Engineering, Suranaree University of Technology, 111 University Avenue Muang, \\ Nakhon Ratchasima 30000, Thailand
}

Correspondence should be addressed to Nitinat Suppakarn; nitinat@sut.ac.th

Received 15 January 2018; Accepted 20 June 2018; Published 25 July 2018

Academic Editor: Carlo Santulli

Copyright (c) 2018 Ladawan Srisuwan et al. This is an open access article distributed under the Creative Commons Attribution License, which permits unrestricted use, distribution, and reproduction in any medium, provided the original work is properly cited.

In this study, the effect of silane treatment methods on cure characteristics and mechanical, dynamic mechanical, and morphological properties of rice husk flour (RHF)/natural rubber (NR) composites was investigated. The RHF surface was pretreated with alkali solution and then treated with bis(triethoxysilylpropyl) tetrasulfide (TESPT) solution using the unwashing silane treatment method and washing silane treatment method. The expected difference between these two methods was the silane layers presented on the RHF surface. Unwashed TESPT-treated RHF (UW-ST) and washed TESPT-treated RHF (W-ST) were incorporated into NR to prepare RHF/NR composites. The TESPT molecules deposited on UW-ST and W-ST surfaces were confirmed by the additional peaks appeared in the FTIR spectra of UW-ST and W-ST. In addition, the decrement of decomposition temperatures and the changes in the residue amounts of UW-ST and W-ST proved the removal of the physisorbed silane layers after washing. The presence of TESPT molecules on the RHF surface enhanced compatibility and adhesion between RHF and NR matrix. This was confirmed by SEM micrographs of both UW-ST/NR and W-ST/NR composites. This result was also supported by the improvement of the mechanical and the dynamic mechanical properties of these two composites. According to mechanical properties of the NR composites, the washing silane treatment method was more effective than the unwashing silane treatment method for compatibility improvement between RHF and NR. The modulus, tensile strength, and tear strength of W-ST/NR composites can be enhanced without deterioration of their elongation at break.

\section{Introduction}

Natural rubber (NR) is one of the major agricultural products of Thailand. NR has been used in several industrial applications, for example, tire, hose, belting, and bridge bearing due to its attractive properties, that is, high tensile strength, high tear strength, and high elasticity. In general, properties of NR products depend on various factors, selected vulcanization systems, and types and properties of added reinforcing fillers etc.

Natural fillers from agricultural sources, for example, sisal, oil palm, wheat straw, wood flour, and rice husk, have extensively gained attention as alternative fillers for NR as well as other polymer systems such as polypropylene and poly-(propylene-co-ethylene) [1-6]. These fillers have advantages over the conventional fillers typically used in NR industries, which are carbon black and silica, in the views of renewability, biodegradability, environmental safety, low density, and low cost [3]. In addition, they also possess interesting properties such as high specific strength and high stiffness. Among those natural fillers, rice husk flour (RHF) is attractive since it is abundantly available in Thailand as a by-product from the rice milling process. RHF contains $45 \%$ cellulose, $19 \%$ hemicelluloses, $19.5 \%$ lignin, and $15 \%$ silica by weight [6]. RHF has been studied and proven to be a good candidate for polymer reinforcement. In addition, utilizing RHF as a reinforcing filler for NR also helps increasing added value of the RHF.

The main problem of RHF/rubber composites is the poor compatibility between hydrophilic RHF and hydrophobic rubber matrix. Several research studies attempted to improve compatibility between them using the addition of compatibilizer or fiber surface modification [5-8]. Fiber surface treatment using alkali solution is well-known method to enhance interfacial adhesion between the filler and polymer matrix. The alkali treatment removes wax, 
hemicellulose, and lignin on RHF surface, producing the surface roughness and active sites. This rough surface not only leads to the increase in interfacial adhesion via mechanical interlocking between RHF and NR but also improves efficiency of other surface treatments applied after alkalization $[8,9]$.

One approach to improve compatibility between RHF and NR is utilization of silane treatment after treating RHF surface with alkali treatment. The use of silane coupling agents can improve the processability of rubber compounds, filler dispersion during mixing, and filler-rubber interaction. The silane coupling agents widely used in rubber composites are $\gamma$-mercaptopropyltrimethoxysilane (MPTS), bis(triethoxysilylpropyl) disulfide (TESPD), bis(triethoxysilylpropyl) tetrasulfide (TESPT), and 3-aminopropyltrimethoxysilane (APTMS) $[9,10]$. Among those, TESPT is an interesting silane coupling agent. The four sulphur atoms in its structure could act as the additional vulcanizing agent leading to the increased cross-link density and the enhanced mechanical properties of NR composites after vulcanization. Moreover, TESPT alters filler surface properties through chemical reaction between TESPT and RHF. The ethoxy groups of TESPT are hydrolyzed and transformed into the silanol groups that can react with the hydroxyl groups of RHF to form the physisorbed or chemisorbed TESPT covered on RHF surface. Chemisorbed silane is the silane that forms at least one covalent bond with the RHF surface, whereas physisorbed silane is the silane that does not form a covalent bond with the RHF surface [11]. Both the chemisorbed silane and physisorbed silane reduce hydrophilicity of RHF and enhance compatibility between RHF and NR matrix. Nevertheless, the presence of these chemisorbed or physisorbed silane layers on the RHF surface may influence physical properties of RHF and RHF/NR composites.

Fukuda et al. [12, 13] and Nakamura et al. [14] studied the effect of silane structure layer on mechanical properties of styrene butadiene rubber composites containing silanetreated inorganic filler. They reported that the chemisorbed silane deposited on the filler surface improved tensile strength and tensile modulus of the composites, whereas the physisorbed silane structure increased their elongation at break. It was also suggested that both the chemisorbed and physisorbed silane molecules enhanced the adhesion between treated filler and polymer matrix, which contributed to the mechanical property improvement of the composites.

In this study, RHF was pretreated with alkali solution prior to silane treatment. The silane coupling agent, TESPT, was used to treat RHF by two different methods, the unwashing method and washing method. The expected difference between these two methods is the silane layers presented on RHF surface. By treating silane on RHF surface using unwashing method, the RHF surface comprised both physisorbed and chemisorbed silane layers. By washing the TESPT-treated RHF, the physisorbed silane molecules were removed, while the chemisorbed silane molecules were still attached on the RHF surface. The dissimilar silane layers on RHF surface may alter the physical properties of the treated RHF/NR composites. Therefore, the aim of this work was to study the effect of silane treatment methods on physical properties of treated RHF and RHF/NR composites.

\section{Materials and Methods}

2.1. Materials. Natural rubber (STR 5L) was purchased from Thai Hua Rubber Public Co., Ltd. Rice husk (RH) was purchased from a local rice mill in Nakhon Ratchasima, Thailand. Sodium hydroxide $(\mathrm{NaOH})$ was purchased from Italma Co., Ltd. Bis(triethoxysilylpropyl) tetrasulfide (TESPT) was obtained from Louis T. Leonowens (Thailand) Co., Ltd. $\mathrm{N}$-cyclohexyl-2 benzothiazole-2-sulfenamide (CBS), stearic acid, zinc oxide ( $\mathrm{ZnO}$ ), and sulphur (S) were supplied by Channel Chemicals Co., Ltd.

2.2. Preparation of RHF. RH was washed thoroughly with tap water to remove the adhered soil and dust and then dried in open air. The dried rice husk was ground using a grinding machine (Retsch ZM200). Then, the rice husk flour (RHF) was sieved with a sieve shaker (Retsch AS200). The RHF retained in sieve size ranging between 150 and $90 \mu \mathrm{m}$ was used. The RHF from this preparation step was called untreated RHF (UT).

Prior to silane treatment, RHF was pretreated with $1 \mathrm{M}$ $\mathrm{NaOH}$ solution at room temperature for $2 \mathrm{~h}$. The treatment time was chosen according to our previous work [15]. Then, the treated RHF was filtered, rinsed several times with water to eliminate the residual $\mathrm{NaOH}$, and dried at $80^{\circ} \mathrm{C}$ for $24 \mathrm{~h}$ in an oven. The treated RHF from alkali pretreatment was called alkali-treated RHF (2ALT).

For silane treatment, bis(triethoxysilylpropyl) tetrasulfide (TESPT), in an amount of 5 wt.\% based on the content of RHF, was dissolved in $90 \%(\mathrm{v} / \mathrm{v})$ ethanol aqueous solution. This TESPT content was selected according to our previous study [16]. To treat the RHF surface, 2ALT was immersed in the prepared TESPT solution at a 2ALT-to-solution ratio of $1: 15$ (w/v) for $3 \mathrm{~h}$. Then, the TESPT-treated RHF (ST) was filtered and dried at $120^{\circ} \mathrm{C}$ for $24 \mathrm{~h}$ in an oven. The ST from this method was called unwashed TESPT-treated RHF (UW-ST). To remove physisorbed silane on the RHF surface, the ST was washed with the $90 \%(\mathrm{v} / \mathrm{v})$ ethanol aqueous solution at room temperature for $30 \mathrm{~min}$ and dried at $120^{\circ} \mathrm{C}$ for $24 \mathrm{~h}$ in an oven. The ST after this method was called washed TESPT-treated RHF (W-ST).

\subsection{Characterization of $R H F$}

2.3.1. Thermal Properties. Thermal decomposition patterns and char residues of untreated RHF and treated RHF were characterized by a thermogravimetric analyzer (TGA) (TA Instruments SDT 2960). Their TGA and DTGA curves were obtained by heating each sample from 25 to $800^{\circ} \mathrm{C}$ at a heating rate of $10^{\circ} \mathrm{C} / \mathrm{min}$ under a nitrogen atmosphere.

2.3.2. Functional Group Analysis. Functional groups of untreated RHF and treated RHF were characterized by a Fourier transform infrared spectrometer (FTIR) (Bruker Tensor 27) using MIRacle single-reflection attenuated total reflectance (ATR) equipped with a platinum diamond crystal (TYPE A225/QL). Their spectra were recorded in wavenumber range from 4000 to $400 \mathrm{~cm}^{-1}$ with a resolution of $4 \mathrm{~cm}^{-1}$ and a number of scans of 64 . 
2.3.3. Morphological Properties. The fiber surfaces of untreated RHF and treated RHF were observed by using a scanning electron microscope (SEM) (JEOL JSM 6010LV) at $10 \mathrm{kV}$. The samples were coated with gold before analysis.

2.4. Preparation of RHF/NR Composites. The RHF was dried in an oven at $80^{\circ} \mathrm{C}$ overnight to discharge the moisture before compounding. The RHF was mixed with NR on a two-roll mill (Chaicharoen) at room temperature for 20 min to prepare NR composites. First, the NR was masticated for $5 \mathrm{~min}$ to reduce its viscosity. Then, stearic acid, zinc oxide, CBS, RHF, and sulphur were respectively added. The formulations of gum NR and NR composites are presented in Table 1. According to our previous works, 2ALT/NR composite at $30 \mathrm{phr}$ of the filler content had higher tensile strength and elongation at break than the untreated RHF/NR composite of the same filler content $[15,16]$. Therefore, in order to investigate the effect of RHF surface treatment methods on properties of NR composites, the RHF content in each formulation was fixed at $30 \mathrm{phr}$.

\subsection{Characterization of RHF/NR Composites}

2.5.1. Cure Characteristics. Cure characteristics of gum NR and $\mathrm{RHF} / \mathrm{NR}$ composites were determined using a moving die rheometer (MDR) (GOTECH/GT-M200F) at a temperature of $150^{\circ} \mathrm{C}$. The scorch time $\left(T_{\mathrm{s}}\right)$, cure time $\left(T_{90}\right)$, maximum torque $\left(S_{\max }\right)$, and minimum torque $\left(S_{\min }\right)$ of the gum NR and RHF/NR composites were determined.

2.5.2. Mechanical Properties. Gum NR and RHF/NR composites were vulcanized at $150^{\circ} \mathrm{C}$ using a compression molding machine (LAB TECH/L320). The vulcanization time was based on the cure time obtained from the MDR measurement. The composite sheet was cut into dumbbell specimens and tear specimens with die cutters (Type $\mathrm{C}$ ). The tensile properties of RHF/NR composites were determined according to ASTM D 412-06a, while tear properties were determined following
TABLE 1: Formulations of gum NR and NR composites.

\begin{tabular}{lcccc}
\hline Materials & \multicolumn{4}{c}{ Content $(\mathrm{phr})$} \\
\hline NR & 100 & 100 & 100 & 100 \\
Zinc oxide & 5 & 5 & 5 & 5 \\
Stearic acid & 1.5 & 1.5 & 1.5 & 1.5 \\
CBS $^{\mathrm{a}}$ & 0.5 & 0.5 & 0.5 & 0.5 \\
Sulphur & 2.5 & 2.5 & 2.5 & 2.5 \\
2ALT & - & 30 & - & - \\
UW-ST & - & - & 30 & - \\
W-ST & - & - & - & 30 \\
\hline
\end{tabular}

${ }^{\mathrm{a}} \mathrm{N}$-cyclohexyl-2 benzothiazole-2-sulfenamide (CBS).

ASTM D 624. The specimens were examined using a universal testing machine (UTM) (Instron 5569) with a load cell of $5 \mathrm{kN}$ and a crosshead speed of $500 \mathrm{~mm} / \mathrm{min}$.

2.5.3. Morphological Properties. Dispersion of RHF and adhesion between the RHF and NR matrix in the RHF/NR composites were characterized using a SEM (JEOL JSM 6010LV). Vulcanized NR composites were immersed in liquid nitrogen and cryogenically fractured. The fracture surfaces were coated with gold and investigated.

2.5.4. Cross-Link Density. The cross-link density $\left(V_{\mathrm{e}}\right)$ of RHF/NR composites was measured according to ASTM D 6814. The vulcanized NR composites were swollen in toluene at $27^{\circ} \mathrm{C}$ for $72 \mathrm{~h}$ until equilibrium swelling stage. Their cross-link density was calculated by the Flory-Rehner equation as follows $[17,18]$ :

$$
V_{\mathrm{e}}=\frac{-\left[\ln \left(1-V_{\mathrm{r}}\right)+V_{\mathrm{r}}+\chi_{1} V_{\mathrm{r}}^{2}\right]}{V_{1}\left[V_{\mathrm{r}}^{1 / 3}-\left(V_{\mathrm{r}} / 2\right)\right]}
$$

where $V_{\mathrm{e}}$ is the effective number of chains in a real network per unit volume, $\chi_{1}$ is the polymer-solvent interaction parameter ( $\chi_{1}$ is 0.391 for toluene), $V_{1}$ is the molecular volume of solvent ( $V_{1}$ is 106.2 in toluene), and $V_{\mathrm{r}}$ is the volume fraction of polymer in swollen network in equilibrium with pure solvent and is calculated as follows [18]:

$$
V_{\mathrm{r}}=\frac{\text { weight of dry rubber/density of dry rubber }}{\text { (weight of dry rubber/density of dry rubber) + (weight of solvent absorbed by sample/density of solvent) }} \text {. }
$$

2.5.5. Dynamic Mechanical Properties. Dynamic mechanical properties of the gum NR and RHF/NR composites were examined using a dynamic mechanical analyzer (GABO EPLEXOR QC 25). The samples were measured in tension deformation mode at a frequency of $1 \mathrm{~Hz}$, a heating rate of $2^{\circ} \mathrm{C} / \mathrm{min}$, and a temperature range from -70 to $80^{\circ} \mathrm{C}$ in a flow of nitrogen.

\section{Results and Discussion}

\subsection{Characterization of $R H F$}

3.1.1. FTIR Analysis. The FTIR spectra of UT, 2ALT, UW-ST, and W-ST are shown in Figure 1. The absorption bands in the spectrum of UT were associated with hemicellulose, cellulose, lignin, and inorganic components in UT $[19,20]$. The broad absorption band at $3333 \mathrm{~cm}^{-1}$ was due to the $\mathrm{O}-\mathrm{H}$ stretching of hydroxyl groups of hemicellulose, cellulose, and lignin in RHF. The absorption band observed at $2917 \mathrm{~cm}^{-1}$ was the characteristics of $\mathrm{C}-\mathrm{H}$ stretching of methyl and methylene groups of hydrocarbon components in RHF. The shoulder band at $1728 \mathrm{~cm}^{-1}$ was assigned to the $\mathrm{C}=\mathrm{O}$ stretching of ester groups in hemicellulose or carboxylic acid groups in lignin. The absorption bands located at $1605 \mathrm{~cm}^{-1}$ and $1515 \mathrm{~cm}^{-1}$ were attributed to $\mathrm{C}=\mathrm{C}$ stretching of the aromatic ring of lignin, while the bands at $1423 \mathrm{~cm}^{-1}$ and $1367 \mathrm{~cm}^{-1}$ were due to the $-\mathrm{CH}_{2}$ and $-\mathrm{CH}$ bending of hemicellulose, cellulose, and lignin. The sharp bands obtained at $1047 \mathrm{~cm}^{-1}$ and $794 \mathrm{~cm}^{-1}$ were, 


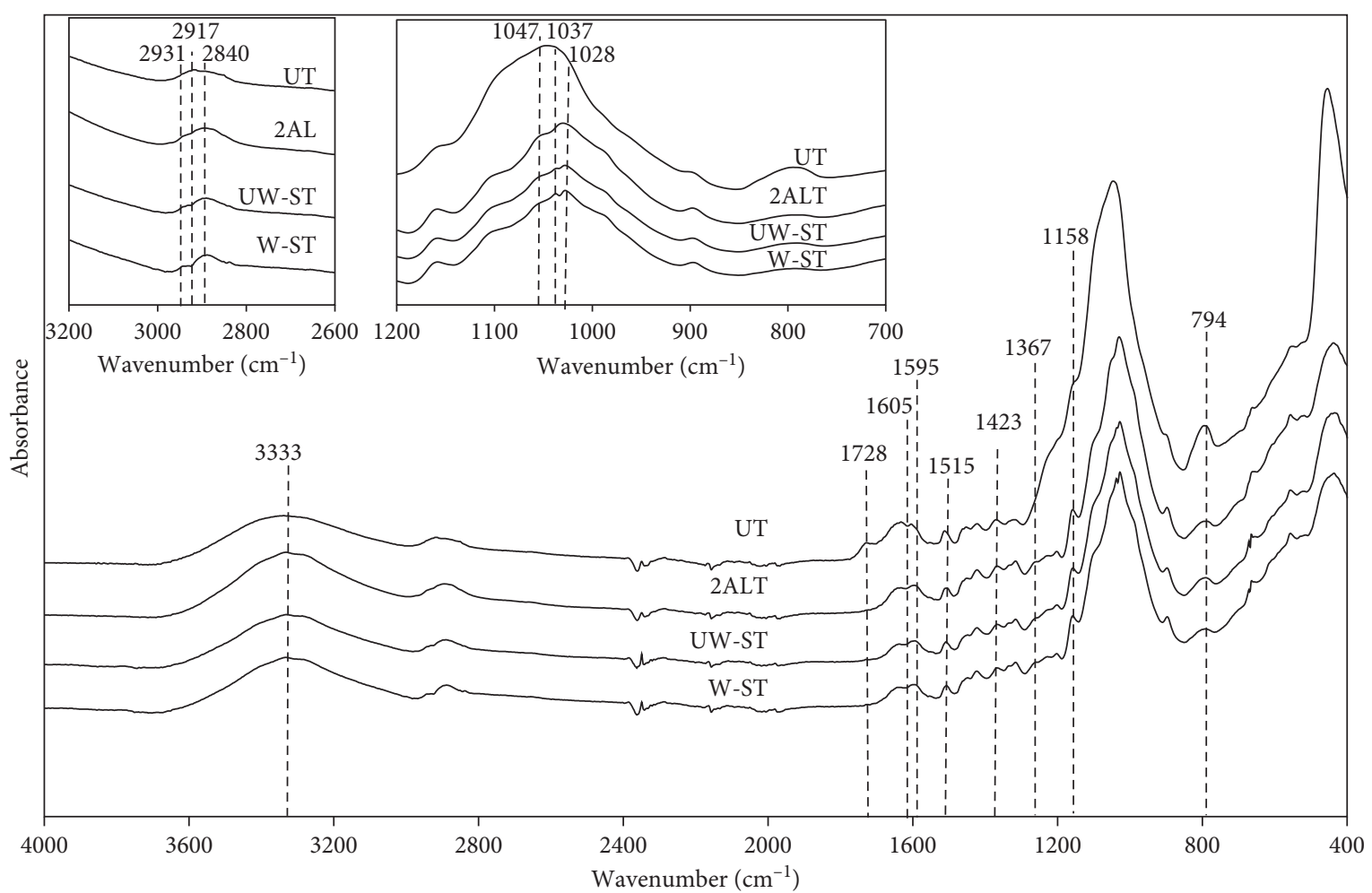

FIgURE 1: FTIR spectra of UT, 2ALT, UW-ST, and W-ST.

respectively, ascribed to the $\mathrm{C}-\mathrm{O}$ stretching of cellulose and the $\mathrm{Si}-\mathrm{O}-\mathrm{Si}$ stretching of silica in RHF.

For the FTIR spectrum of the RHF after alkali treatment (2ALT), the C-H stretching vibration band of 2 ALT moved to $2840 \mathrm{~cm}^{-1}$ as compared with that of UT. This indicated that alkali treatment removed hemicellulose and lignin from the RHF surface [21]. Further evidence of the removal of hemicellulose and lignin by alkali treatment was supported by the disappearance of the $\mathrm{C}=\mathrm{O}$ stretching band at $1728 \mathrm{~cm}^{-1}$ and the shifts of the $\mathrm{C}=\mathrm{C}$ and the $\mathrm{C}-\mathrm{O}$ stretching bands to $1595 \mathrm{~cm}^{-1}$ and $1028 \mathrm{~cm}^{-1}$, respectively. Moreover, the intensity of $\mathrm{Si}-\mathrm{O}-\mathrm{Si}$ stretching band at $794 \mathrm{~cm}^{-1}$ reduced after treating with alkali solution. This was because alkali treatment also removed partial silica from the RHF surface.

After silane treatment, the FTIR spectra of both UW-ST and W-ST revealed the additional absorption bands as compared with that of $2 \mathrm{ALT}$. The small band that occurred at $2931 \mathrm{~cm}^{-1}$ was the stretching vibration of the $-\mathrm{CH}_{2}$ groups of the attached TESPT on UW-ST and W-ST surface [22]. Another absorption band that emerged at $1037 \mathrm{~cm}^{-1}$ was related to the $\mathrm{Si}-\mathrm{O}-\mathrm{Si}$ stretching of the siloxane groups of TESPT on UW-ST and W-ST surface [23]. The appearance of these two absorption bands implied that TESPT could react with hydroxyl groups on 2ALT surface by physical or chemical bonding. Nonetheless, the difference between physisorbed and chemisorbed silane layers cannot be observed from their FTIR spectra.

3.1.2. Thermal Properties. TGA and DTGA thermograms of UT, 2ALT, UW-ST, and W-ST are illustrated in Figure 2. UT, 2ALT, UW-ST, and W-ST started their initial weight loss below $100^{\circ} \mathrm{C}$ due to the evaporation of adsorbed water. All treated RHF samples showed lower adsorbed water content than UT. This indicated that alkali and silane treatment reduced moisture adsorption on the treated RHF surface. Furthermore, DTGA thermograms of UT showed peaks at $303^{\circ} \mathrm{C}, 353^{\circ} \mathrm{C}$, and $536^{\circ} \mathrm{C}$. These peaks were, respectively, attributed to the decomposition of hemicellulose, cellulose, and lignin $[4,19,20]$. The residue content of UT observed at $800^{\circ} \mathrm{C}$ was $30 \mathrm{wt} . \%$ which composed of the mixtures of carbonaceous products and silica [4].

After alkali treatment, the DTGA thermogram of 2ALT presented only a cellulose decomposition peak at around $356^{\circ} \mathrm{C}$. The decomposition peak of $2 \mathrm{ALT}$ was higher than that of UT. This result was because alkali treatment removed hemicellulose and lignin from RHF and resulted in the increase in the relative content of cellulose [24]. The removal of hemicellulose and lignin from the RHF surface by alkali treatment was also confirmed by the absence of hemicelluloses and lignin decomposition peaks at $303^{\circ} \mathrm{C}$ and $536^{\circ} \mathrm{C}$. This result agreed well with the disappearance of $\mathrm{C}=\mathrm{O}$ stretching absorption bands from the FTIR spectrum of 2ALT as shown in Figure 1. The residue content at $800^{\circ} \mathrm{C}$ of 2ALT was lower than that of UT. This result may be due to the removal of some silica during alkali treatment.

After silane treatment, UW-ST and W-ST revealed the cellulose decomposition peak at around $354^{\circ} \mathrm{C}$. These decomposition temperatures of both UW-ST and W-ST were slightly lower than that of 2ALT. The decreased decomposition temperatures of UW-ST and W-ST were due to the decomposition of TESPT molecules attached on the UW-ST and W-ST surfaces. This result was supported by 


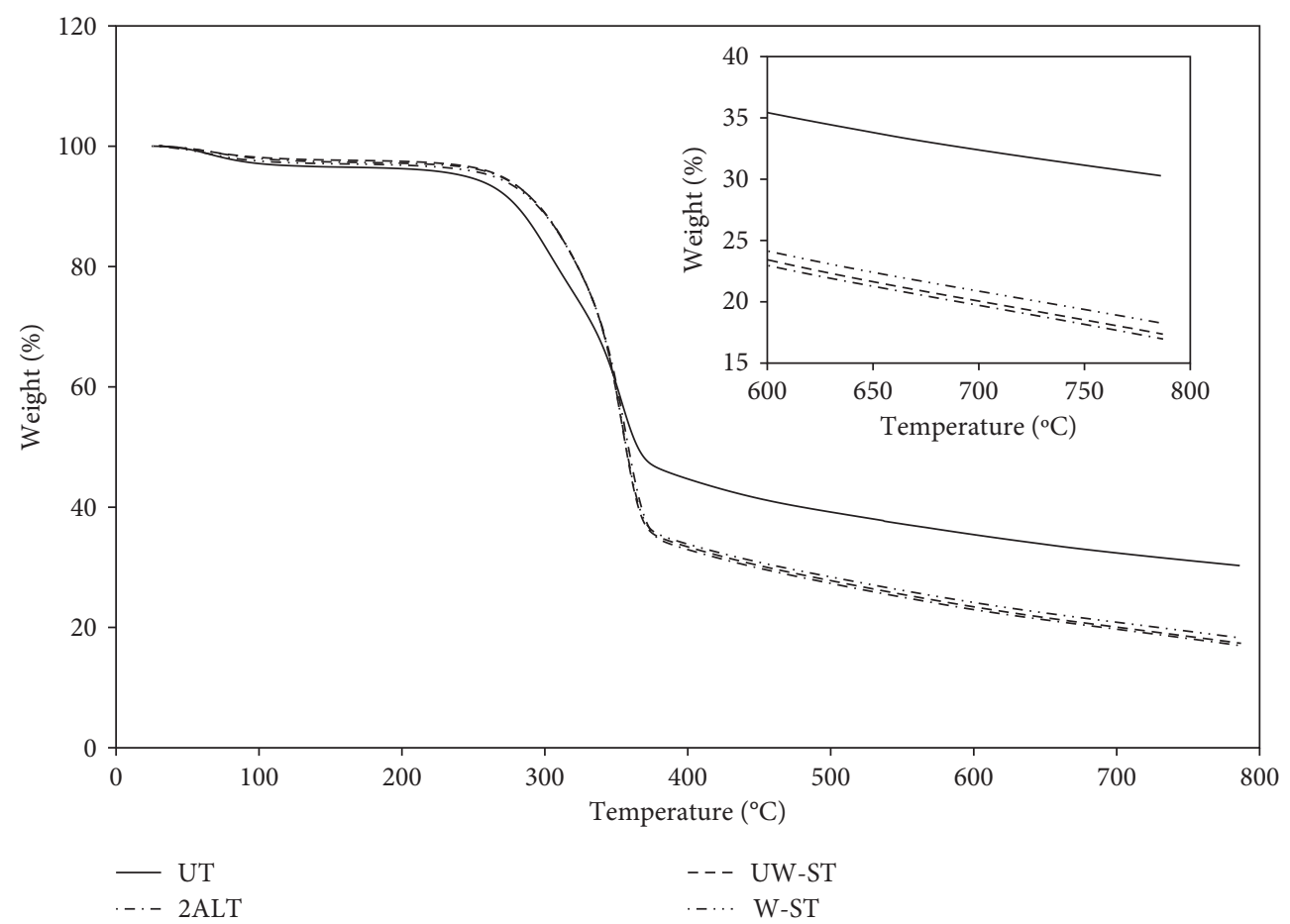

(a)

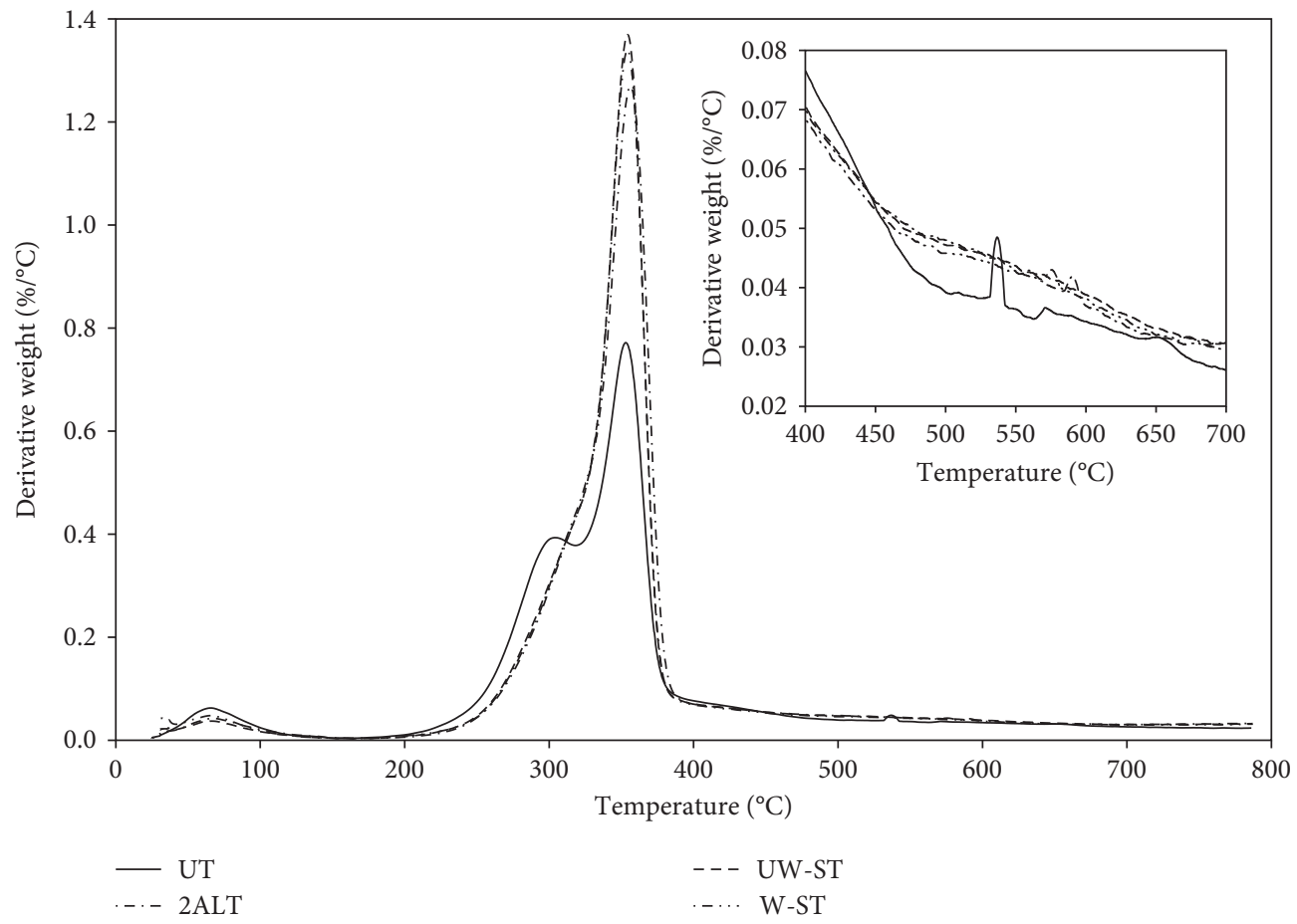

(b)

FIgURE 2: TGA (a) and DTGA (b) thermograms of UT, 2ALT, UW-ST, and W-ST.

the appearance of new absorption bands in the FTIR spectra of UW-ST and W-ST as shown in Figure 1. Among ALT, UW-ST, and W-ST, the residue amount of W-ST was the highest, while that of ALT was the lowest. The result was attributed to the TESPT layers on UW-ST and W-ST surfaces. In this study, the ethoxy groups of TESPT were hydrolyzed and changed to silanol groups which could react with the hydroxyl groups of RHF. This reaction resulted in the occurring of chemisorbed or physisorbed TESPT layers on RHF surface. In case of unwashing silane treatment, UW-ST had both chemisorbed and physisorbed TESPT on its surface leading to the increase in the silane 
layers including its silicon atoms and organic contents. Therefore, the higher attached TESPT content on UW-ST surface led to less residue of the UW-ST. Therefore, the TGA analysis suggested the removal of the physisorbed silane layers after washing. A similar result was reported by Fukuda et al. in their work on silica particle-filled styrene butadiene rubber composites $[12,13]$. They suggested that the increased residue of TESPD-treated silica after washing was attributed to the difference in amounts of silane layers on silica surface as compared with that of unwashed TESPD-treated silica.

3.1.3. Morphological Properties. Figures 3(a)-3(h) show SEM micrographs of the outer and inner surfaces of UT, 2ALT, UW-ST, and W-ST. From Figure 3(a), it can be seen that the outer UT surface was covered with impurities, which may possibly be wax pectin and cement materials [24]. In addition, the inner surface of UT (Figure 3(b)) seemed to be smoother than its outer surface. After alkali treatment, the outer surface of 2ALT (Figure 3(c)) was rougher than that of UT. This implied that alkali treatment removed some components, that is, hemicellulose and lignin, from the RHF surface [24]. The inner surface of 2ALT (Figure 3(d)) was insignificantly different from the inner surface of UT. After silane treatment, the outer and inner surfaces of UW-ST and W-ST (Figures 3(e)-3(h)) were similar to that of 2ALT. This may be because of the low content of TESPT attached on RHF surface.

\subsection{Characterization of RHF/NR Composites}

3.2.1. Cure Characteristic. Scorch time and cure time of gum NR, 2ALT/NR, UW-ST/NR, and W-ST/NR composites are shown in Figure 4. Scorch time and cure time of the 2ALT/NR composite insignificantly changed as compared with those of the gum NR. The observed results may be due to the compromise between the premature cross-linking during the NR composite compounding and the adsorption of chemical agents by the RHF surface. As compared with gum NR compounding, NR composites required a longer compounding time due to the addition of RHF. The long compounding time led to the high heat buildup and resulted in the formation of premature cross-linking in the NR composites. The presence of premature cross-linking led to the reduced scorch time and cure time of the NR composites. Contrarily, the adsorption of rubber chemical agents by the RHF surface prolonged the scorch time and cure time of the NR composites [25]. As the result, the insignificant change in scorch time and cure time of the gum NR and 2ALT/NR composite was observed.

For NR composites containing RHF of different surface treatments, the scorch time and the cure time of 2ALT/NR and UW-ST/NR composites had similar values. However, the scorch time and the cure time of the W-ST/NR composite were slightly longer than those of the UW-ST/NR composite. This was due to the good filler-rubber interaction. The sulphur atoms of the chemisorbed TESPT on the W-ST surface were dissociated by heating and reacted with the rubber chains to form cross-links between W-ST and the NR matrix. The increase in cross-link density of W-ST/NR composite as compared with other NR composites was observed and is reported in Figure 6. These chemical bonds between W-ST and NR improved filler-rubber interaction of NR composites. Similar results were found by Jacob et al. [1], Ismail et al. [26], and Sahakaro and Beraheng [27]. They suggested that the prolonged scorch time and cure time of NR composites resulted from the better interaction between the filler and rubber matrix. In addition, the increase in scorch time and cure time of NR composites containing TESPT was also reported in natural rubber reinforced with short cellulose fiber/silica [22], natural rubber filled with fly ash [28], and natural rubber reinforced with silica [28].

Minimum torque, maximum torque, and torque difference of gum NR, 2ALT/NR, UW-ST/NR, and W-ST/NR composites are presented in Figure 5. Minimum torque can be related to the viscosity of the NR compound before vulcanization and influenced by mixing time and filler properties [29]. The minimum torque of 2 ALT/NR composite was similar to that of gum NR. This may be due to the stiffness reduction of 2ALT after alkali treatment. Alkali treatment removed hemicellulose and lignin components from RHF surface which probably decreased the rigidity of RHF [9]. The minimum torque of the UW-ST/NR and W-ST/NR composites was slightly higher than that of the 2ALT/NR composite. This was because the TESPT layers on the UW-ST and W-ST surfaces enhanced entanglement of rubber chains and resulted in the increased viscosity of the rubber composite compounds. However, the minimum torques of UW-ST/NR and W-ST/NR composites were insignificantly different. These indicated that both silane treatment methods were not much affected on minimum torque of these two NR composites.

The maximum torque was related to the modulus of NR compounds after vulcanization. The maximum torque of 2ALT/NR composite was similar to that of gum NR. This result indicated that the alkali treatment could not improve interaction between the RHF and NR matrix. On the other hand, after treating the RHF surface with a silane coupling agent, the maximum torques of UW-ST/NR and W-ST/NR composites slightly increased as compared with that of the 2ALT/NR composite. This observation suggested that TESPT on the UW-ST and W-ST surface enhanced fillerrubber interaction and resulted in the reduction of the mobility of rubber's molecular chains in NR composites.

The difference between the maximum torque and minimum torque or torque difference is indirectly related to cross-link density of rubber compounds [30]. The torque difference of the $2 \mathrm{ALT} / \mathrm{NR}$ composite was not changed as compared with that of the gum NR. This was due to the poor interaction between the 2ALT and NR matrix. After silane treatment, the torque differences of the UW-ST/NR and W-ST/NR composites were higher than that of the 2ALT/NR composite. This implied that TESPT on the UWST and W-ST surface increased filler-rubber interaction and enhanced cross-link density of NR composites. This result was well supported by the cross-link density result as shown in Figure 6. The increment of cross-link density of the 


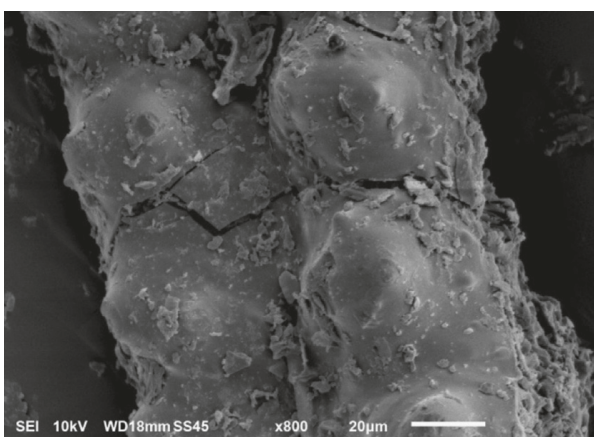

(a)

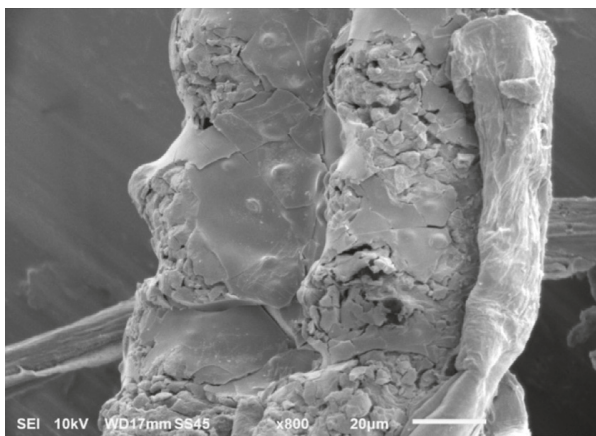

(c)

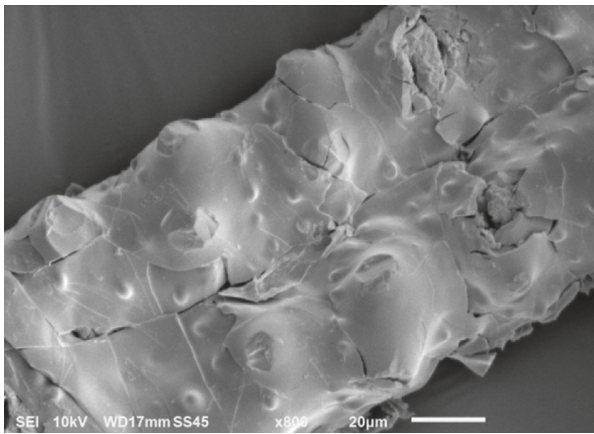

(e)

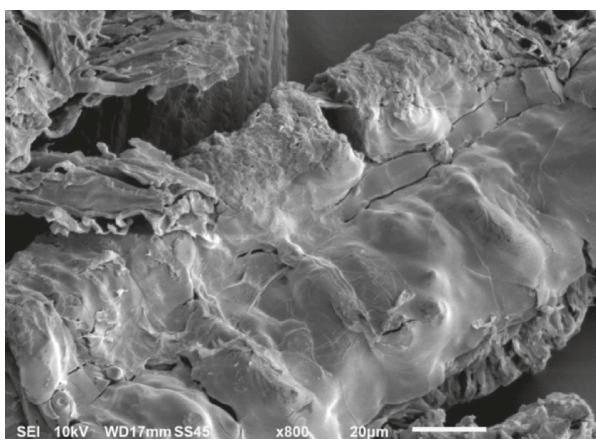

(g)

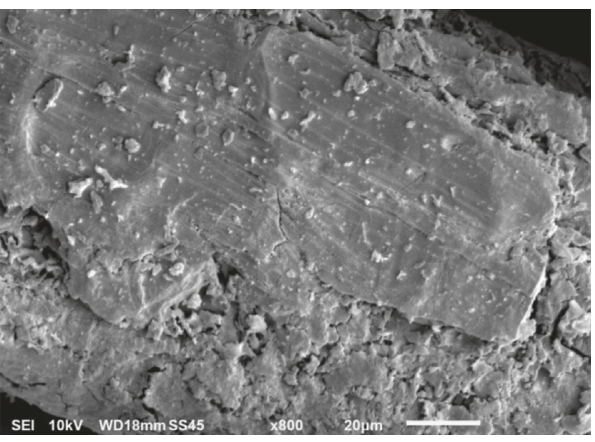

(b)

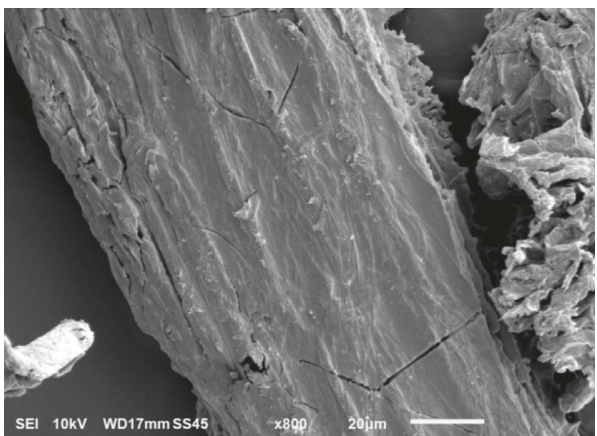

(d)

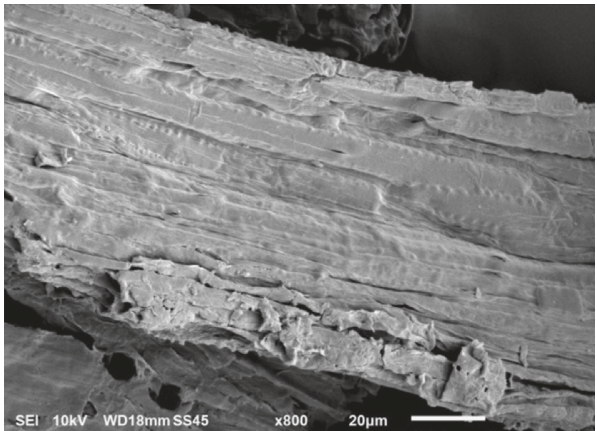

(f)

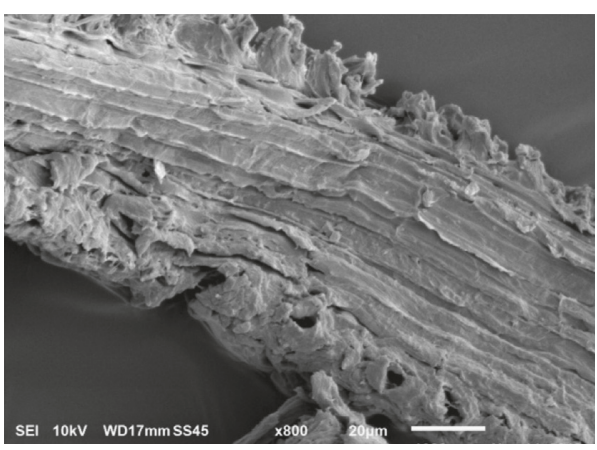

(h)

Figure 3: SEM micrographs of outer and inner surfaces of (a-b) UT, (c-d) 2ALT, (e-f) UW-ST, and (g-h) W-ST.

UW-ST/NR and W-ST/NR composites was because the presence of TESPT on the UW-ST and W-ST surface increased the sulphur contents in both NR composites. The sulphur atoms in the TESPT molecules on UW-ST and W-ST were dissociated and reacted with the rubber chain during the vulcanization process, resulting in the enhanced sulphur cross-link in the composites. However, the torque difference of the UW-ST/NR composite was slightly lower than that of the $\mathrm{W}-\mathrm{ST} / \mathrm{NR}$ composite. This may be because the long chain of physisorbed TESPT on UW-ST surface reduced 


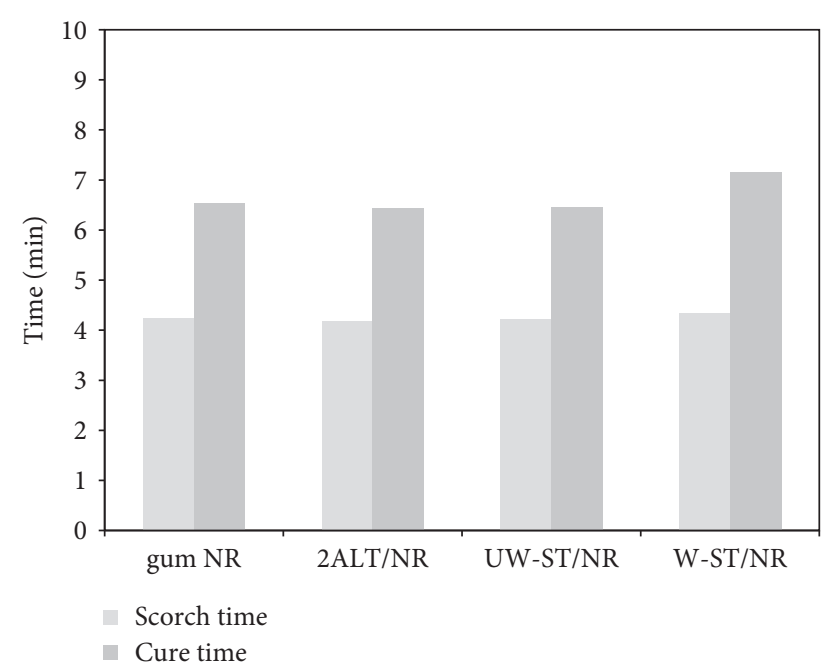

FIGURE 4: The scorch time and cure time of gum NR, 2ALT/NR, UW-ST/NR, and W-ST/NR composites.

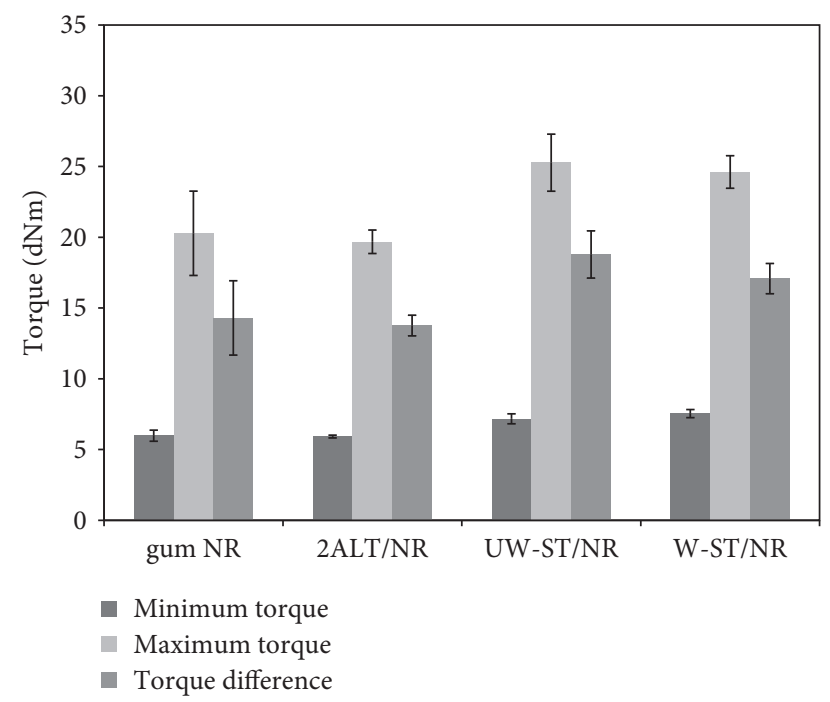

Figure 5: Minimum torque, maximum torque, and torque difference of gum NR, 2ALT/NR, UW-ST/NR, and W-ST/NR composites.

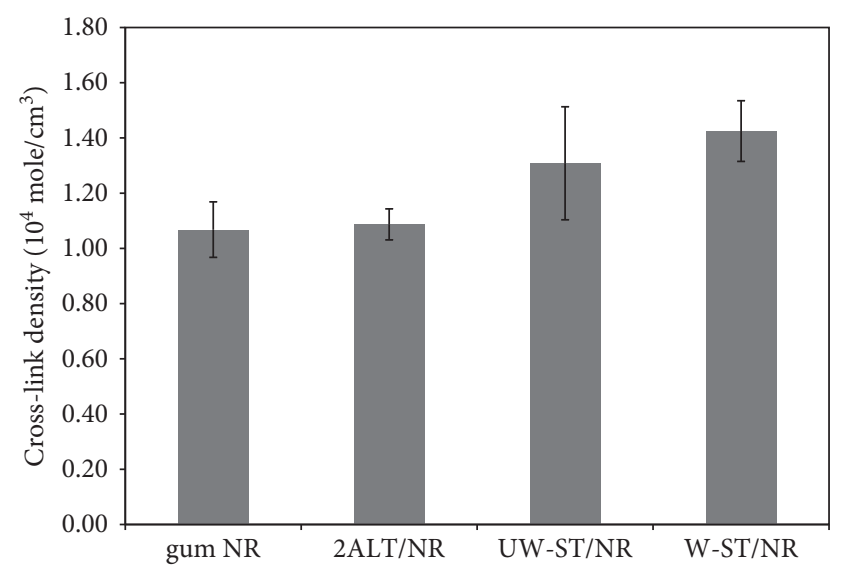

FIGURE 6: Cross-link density of gum NR, 2ALT/NR, UW-ST/NR, and $\mathrm{W}-\mathrm{ST} / \mathrm{NR}$ composites. cross-linking reaction between the silane molecules and NR matrix and resulted in the lower cross-link density of the UW-ST/NR composite [14].

3.2.2. Cross-Link Density. Figure 6 represents the cross-link density of gum NR, 2ALT/NR, UW-ST/NR, and W-ST/NR composites. The main constituents of RHF are hemicellulose, cellulose, lignin, and silica. Therefore, the RHF surface contains numerous hydroxyl groups, which can adsorb curing agents, as parts of those chemical components. As a result, the addition of filler having hydroxyl groups on its surface generally reduces the cross-link density of rubber composites [25]. From Figure 6, the cross-link density of 2ALT/NR composite was similar to that of gum NR. This indicated that the alkali treatment may reduce the filler surface adsorption of curative agents by the removal of some hydroxyl groups on RHF surface. After treating with silane treatment, the cross-link density of UW-ST/NR and W-ST/NR composites slightly increased as compared with that of the 2ALT/NR composite. The cross-link formations of NR composites containing TESPT-treated RHF can occur via two vulcanization reactions, that is, (1) reaction of NR molecules with the added sulphur cross-linking agent and (2) reaction of NR molecules with the sulphur dissociated from TESPT [9]. However, the W-ST/NR composite exhibited a higher cross-link density than the UW-ST/NR composite. This was attributed to the effect of TESPT on the filler surface. The W-ST surface contained only chemisorbed TESPT, while the UW-ST surface combined both the physisorbed and chemisorbed TESPT. The presence of chemisorbed TESPT on the W-ST surface may enhance cross-link reaction between NR molecules and W-ST. In contrast, the existence of self-agglomeration of physisorbed TESPT on the UW-ST surface may inhibit cross-link reaction between the NR matrix and sulphur from TESPT resulting in the lower cross-link density of the UW-ST/NR composite [19]. The result of cross-link density was in good agreement with those of torque difference, tensile properties, and tear properties of NR composites.

3.2.3. Mechanical Properties. Stress-strain curves of gum NR, 2ALT/NR, UW-ST/NR, and W-ST/NR composites are presented in Figure 7. For the gum NR, the stress increased along with increasing strain. This high stress was attributed to the strain-induced crystallization behavior of NR [1]. The addition of RHF into the NR matrix interrupted straininduced crystallization of NR resulting in the decrease in elongation of NR composites. However, at below $1000 \%$ strain, the stress of all NR composites was higher than that of the gum NR. The improvement of stress of the NR composites was because surface treatment enhanced interfacial adhesion between the treated RHF and NR matrix. Among NR composites, W-ST/NR composites showed the highest stress. This result indicated that the washing surface treatment effectively improved interfacial adhesion between the RHF and NR than the unwashing surface treatment. In addition, the high stress of the W-ST/NR composites resulted from the cross-linking reaction between sulphur 


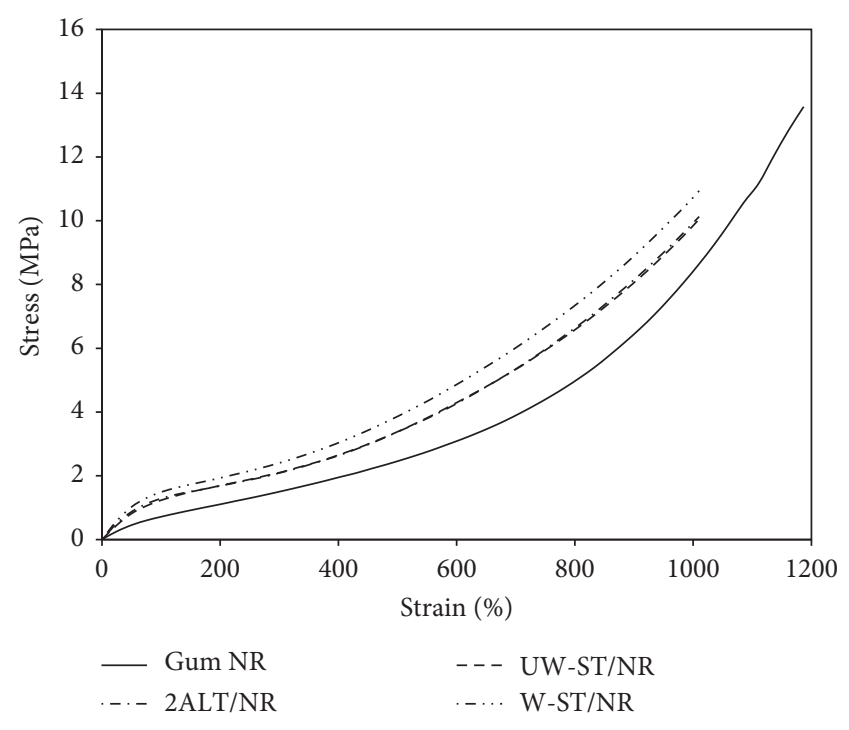

Figure 7: Stress-strain curves of gum NR, 2ALT/NR, UW-ST/NR, and $\mathrm{W}-\mathrm{ST} / \mathrm{NR}$ composites.

molecules of TESPT on the RHF surface and rubber molecules. On the other hand, the stress of the UW-ST/NR composites was similar to that of the 2ALT/NR composites. The result was because the physisorbed TESPT molecules on UW-ST surface may act as a plasticizer in NR matrix resulting in the constant stress of UW-ST/NR composites [28].

M100 and M300 of gum NR and NR composites are illustrated in Figure 8. As seen, M100 and M300 of NR composites were higher than that of gum NR. This was because the incorporation of RHF into the NR matrix enhanced the stiffness of NR composites. Among the NR composites, the W-ST/NR composite showed the highest values of M100 and M300 while those of the 2ALT/NR and UW-ST/NR composites were similar. This result was associated with the highest cross-link density of the W-ST/NR composite and the increased interfacial adhesion between the W-ST and NR matrix. The UW-ST/NR composite showed similar values of M100 and M300 to the 2ALT/NR composite although it had a higher cross-link density. This may be because of the plasticizing effect of the physically adsorbed TESPT molecules on the UW-ST surface [28].

Figure 9 shows the tensile strength and elongation at the break of gum NR, 2ALT/NR, UW-ST/NR, and W-ST/NR composites. The tensile strength of gum NR was higher than those of the NR composites. This was because of the straininduced crystallization of NR [1]. With the incorporation of RHF into NR, RHF interrupted the arrangement of the NR chain resulting in the reduction of the strain-induced crystallization ability of the NR leading to the decrement of tensile strength of the NR composites [1,3]. As compared with the 2ALT/NR composite, the tensile strength of the UW-ST/NR and W-ST/NR composites slightly increased. The change in tensile strength of both NR composites was due to filler-rubber interaction enhancement after treating the RHF surface with the silane coupling agent. The TESPT used in this study was hydrolyzed and formed as silanol groups. The silanol groups of the TESPT could form

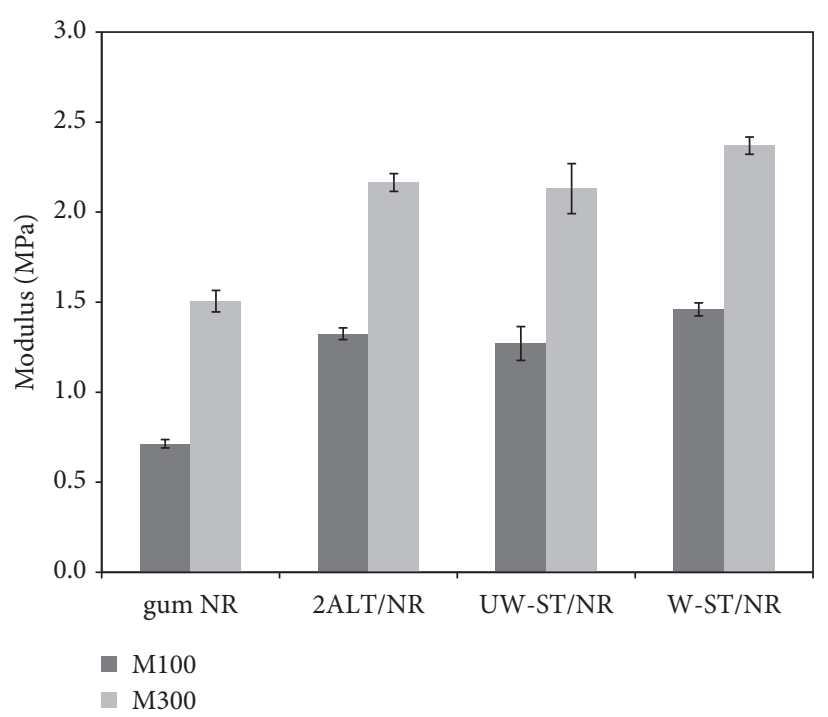

FIGURE 8: M100 and M300 of gum NR, 2ALT/NR, UW-ST/NR, and W-ST/NR composites.

physisorbed or chemisorbed layers on the RHF surface while the sulphur atoms in the TESPT could dissociate and react with rubber chains $[11,12]$. This reaction enhanced fillerrubber interaction. Additionally, the SEM micrograph of NR composites in Figure 10 also supported the improvement of tensile properties. The SEM of all composites showed the RHF embedded in the NR matrix. Particularly, UW-ST/NR and W-ST/NR composites exhibited the adhered NR on RHF surface indicating the good filler-rubber interaction in these NR composites. In addition, the increment of tensile strength of UW-ST/NR and W-ST/NR composites was the result of the increased cross-link density in Figure 6. In case of the UW-ST/NR composite, the physisorbed TESPT on the UW-ST surface acted as a plasticizer in the NR composites which inhibited the cross-link reaction between TESPT and NR, leading to the low cross-link density of the UWST/NR composite. Therefore, the tensile strength of the UW-ST/NR composite was slightly lower than that of the W-ST/NR composite.

Elongation at break of the gum NR was higher than those of the NR composites. The reduced elasticity of the NR composites was because the RHF restricted the mobility of the rubber chains. As compared with the 2ALT/NR composite, elongation at break of the UW-ST/NR and W-ST/NR composites slightly increased. The changes in elongation at break of both the NR composites were associated with the improvement of filler dispersion and filler-rubber interaction. However, there was no significant difference between the elongation at break of the UW-ST/NR and W-ST/NR composites.

Figure 10 presents the tear strength of gum NR, $2 A L T / N R, U W-S T / N R$, and W-ST/NR composites. It can be seen that the tear strength of the NR composites was lower than that of the gum NR. This was because the addition of RHF into NR restricted strain-induced crystallization behavior of rubber chains. In addition, the reduction of the tear strength may be because of the packed fibers in the rubber 


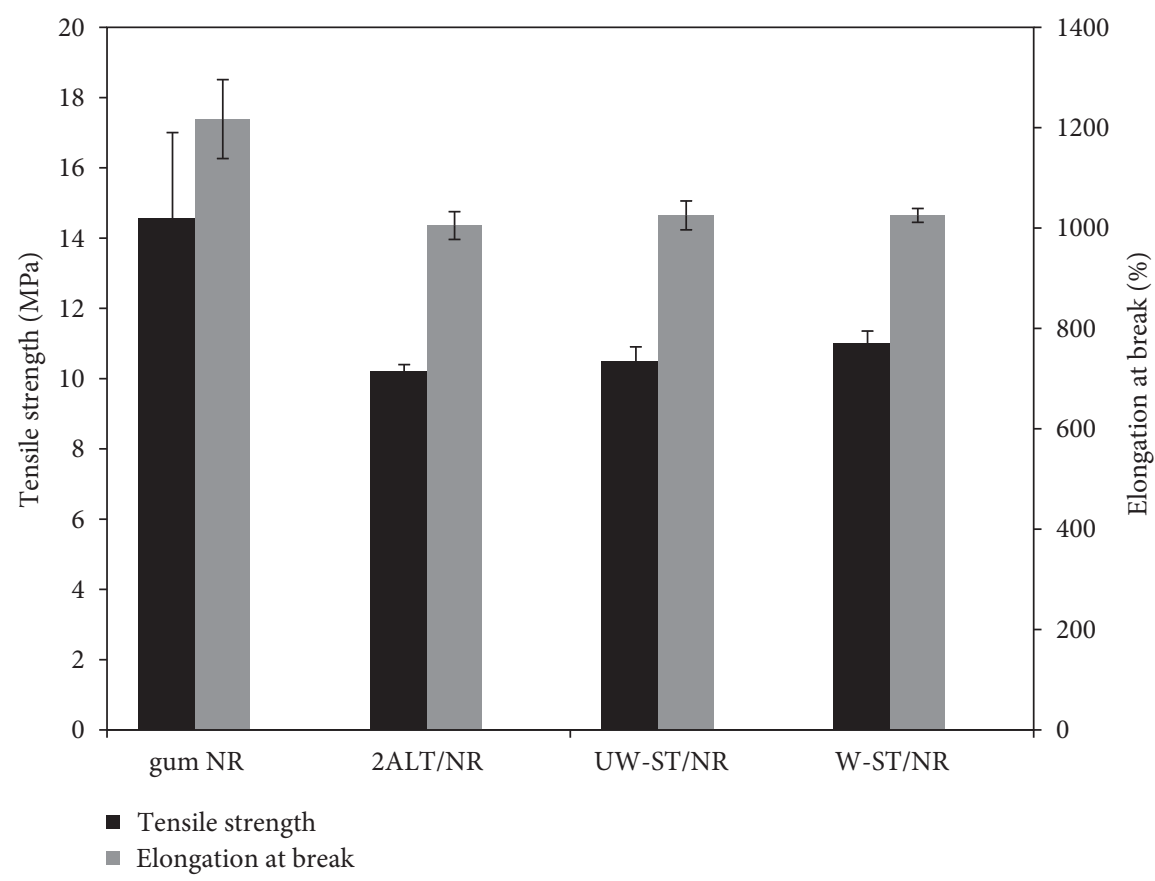

Figure 9: Tensile strength and elongation at break of gum NR, 2ALT/NR, UW-ST/NR, and W-ST/NR composites.

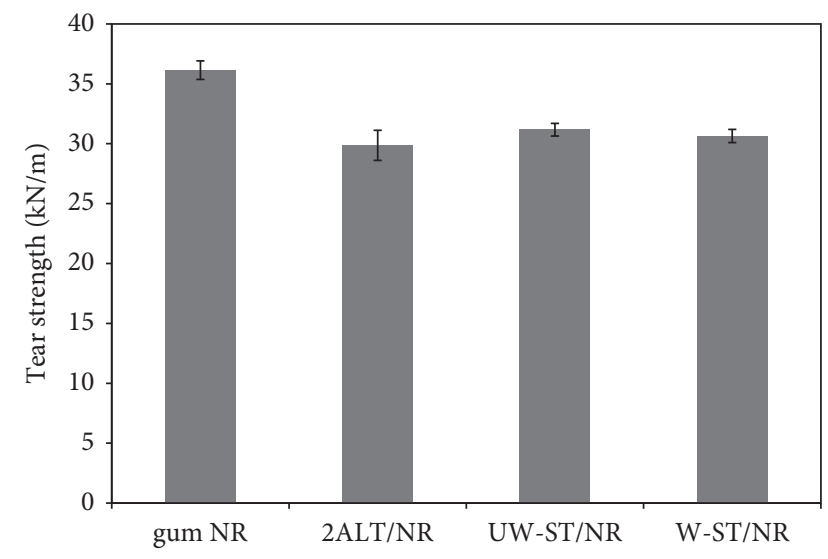

Figure 10: Tear strength of gum NR, 2ALT/NR, UW-ST/NR, and W-ST/NR composites.

matrix. When tearing force was applied to the composites, the fiber in NR matrix was closely packed, resulting in the enlarged tearing and the reduced tear strength of rubber composites [31]. In comparison, the UW-ST/NR and $\mathrm{W}-\mathrm{ST} / \mathrm{NR}$ composites gave higher tear strength than the 2ALT/NR composite. This suggested that treating the RHF surface with TESPT improved filler-rubber interaction and filler dispersion in the NR matrix. Nonetheless, the tear strength of both the UW-ST/NR and W-ST/NR composites was not different.

According to mechanical properties of the NR composites containing an RHF of $30 \mathrm{phr}$, the results indicated that the washing silane treatment method was a more effective method than the unwashing silane treatment method for compatibility improvement between RHF and NR. As compared with those of the 2ALT/NR composite, the modulus, tensile strength, and tear strength of the W-ST/NR composite can be improved, by $12 \%, 10 \%$, and $5 \%$, respectively, without deterioration of the elongation at break.

3.2.4. Morphological Properties. SEM micrographs of the cryogenic fracture surface of gum NR, 2ALT/NR, UWST/NR, and W-ST/NR composites are shown in Figure 11. Morphologies of all NR composites showed the embedded RHF in NR matrix. The gap between RHF and NR matrix in 2ALT/NR composite was observed in Figure 11(b). This indicated the weak adhesion between RHF and NR matrix. After silane treatment, the morphologies of the UW-ST/NR and W-ST/NR composites in Figures 11(c) and 11(d) illustrated the attached NR on the RHF surface. This implied that TESPT on the UW-ST and W-ST surfaces may enhance filler-NR matrix interaction in these two NR composites [23]. This result supported the tensile properties improvement of the UWST/NR and W/NR composites. Nonetheless, the morphologies of the fracture surfaces of the UW-ST/NR and W-ST/NR composites cannot be differentiated.

3.2.5. Dynamic Mechanical Properties. Storage modulus, as a function of temperature, of gum NR, 2ALT/NR, UWST/NR, and W-ST/NR composites is shown in Figure 12. The storage modulus measures the recoverable strain energy in a deformed specimen which implies elastic modulus of that material. It can be seen that in the glassy region, the storage modulus of gum NR was slightly higher than those of the $2 \mathrm{ALT} / \mathrm{NR}$ and UW-ST/NR composites. This was due to the inherent semicrystalline characteristics of NR. In the rubbery region, the storage modulus of all NR composites was higher than that of the gum NR. This was because the 


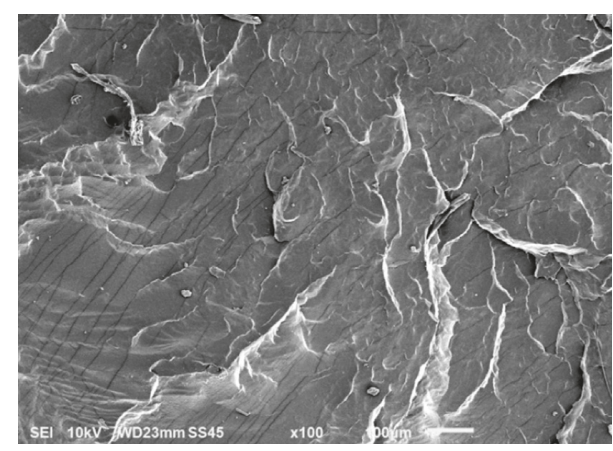

(a)

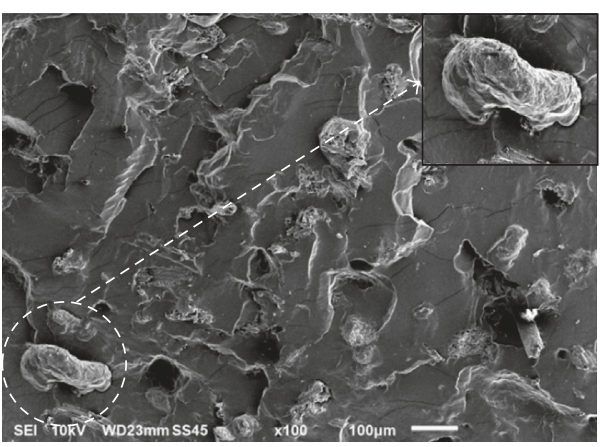

(c)

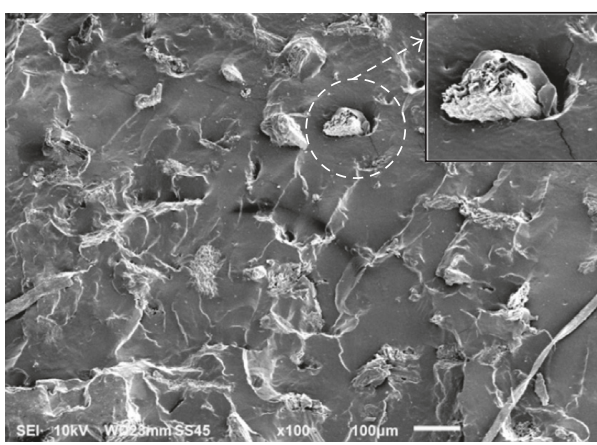

(b)

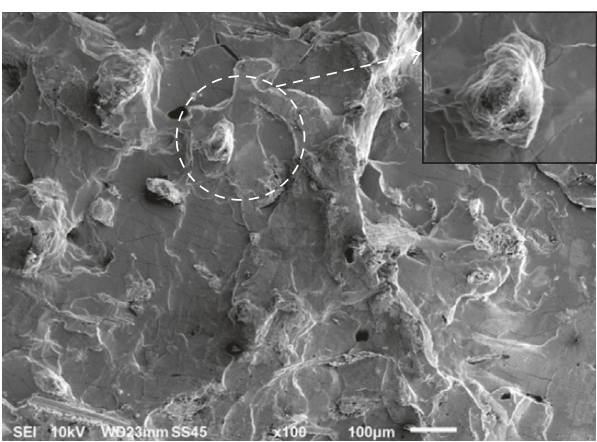

(d)

Figure 11: SEM micrographs of fracture surface of (a) gum NR, (b) 2ALT/NR, (c) UW-ST/NR, and (d) W-ST/NR composites.

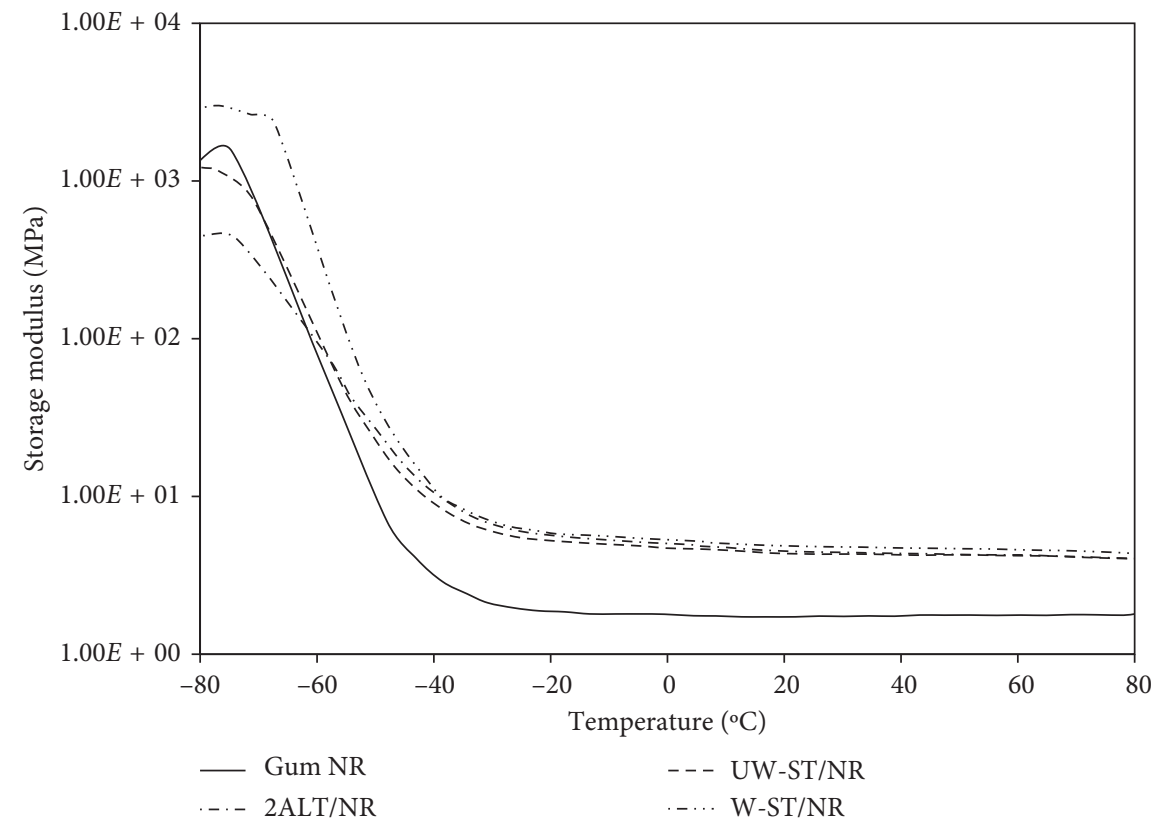

Figure 12: Storage modulus of gum NR, 2ALT/NR, UW-ST/NR, and W-ST/NR composites.

dispersed RHF in the NR matrix enhanced the stiffness of the systems. Furthermore, the high storage modulus of the NR composites may be attributed to the formation of cross-link within the rubber matrix-filler network resulting in the increase in stiffness of the NR composites. Among all NR composites, the storage modulus of the W-ST/NR composite was the highest. This result was because TESPT on the W-ST surface improved RHF dispersion in the NR matrix and enhanced interaction between them [32].

Figure 13 shows the loss modulus, as a function of temperature, of gum NR, 2ALT/NR, UW-ST/NR, and $\mathrm{W}-\mathrm{ST} / \mathrm{NR}$ composites. The loss modulus of a material is related to the energy that is dissipated as heat under an oscillating force. In the glassy region, the loss modulus of all 


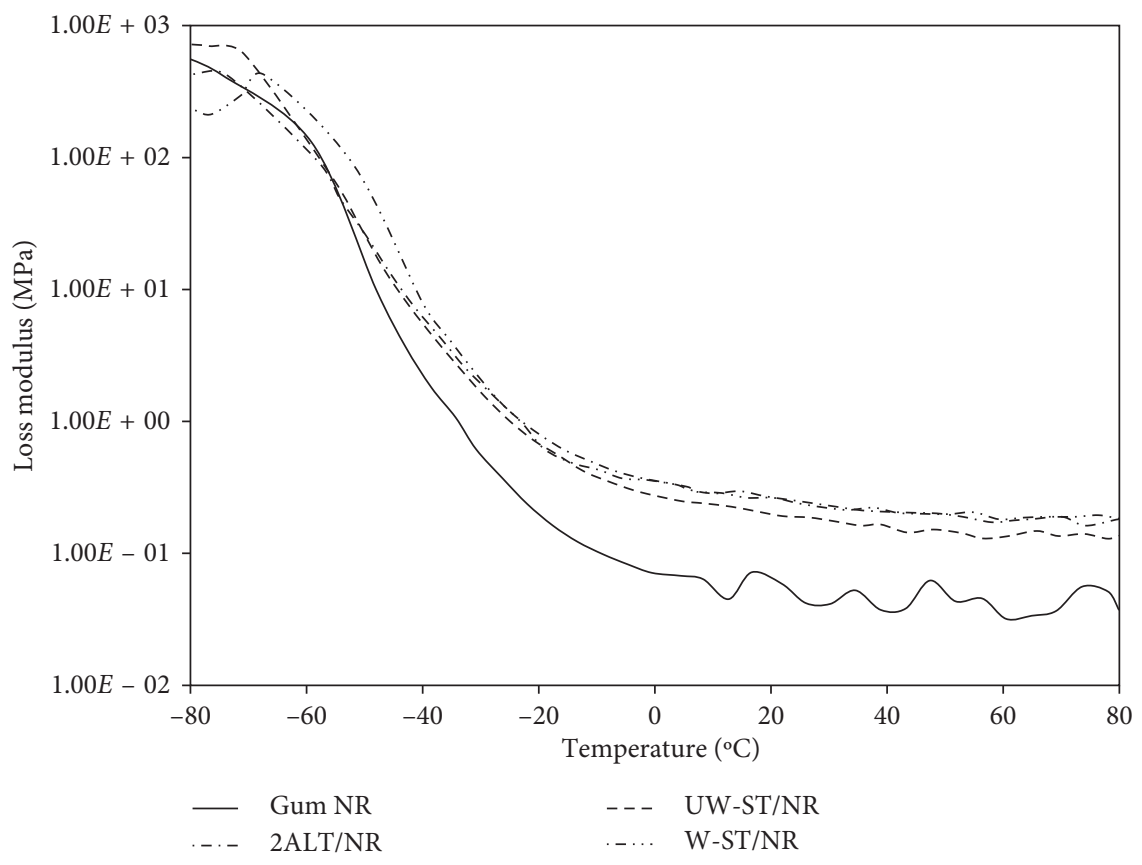

FIGURE 13: Loss modulus of gum NR, 2ALT/NR, UW-ST/NR, and W-ST/NR composites.

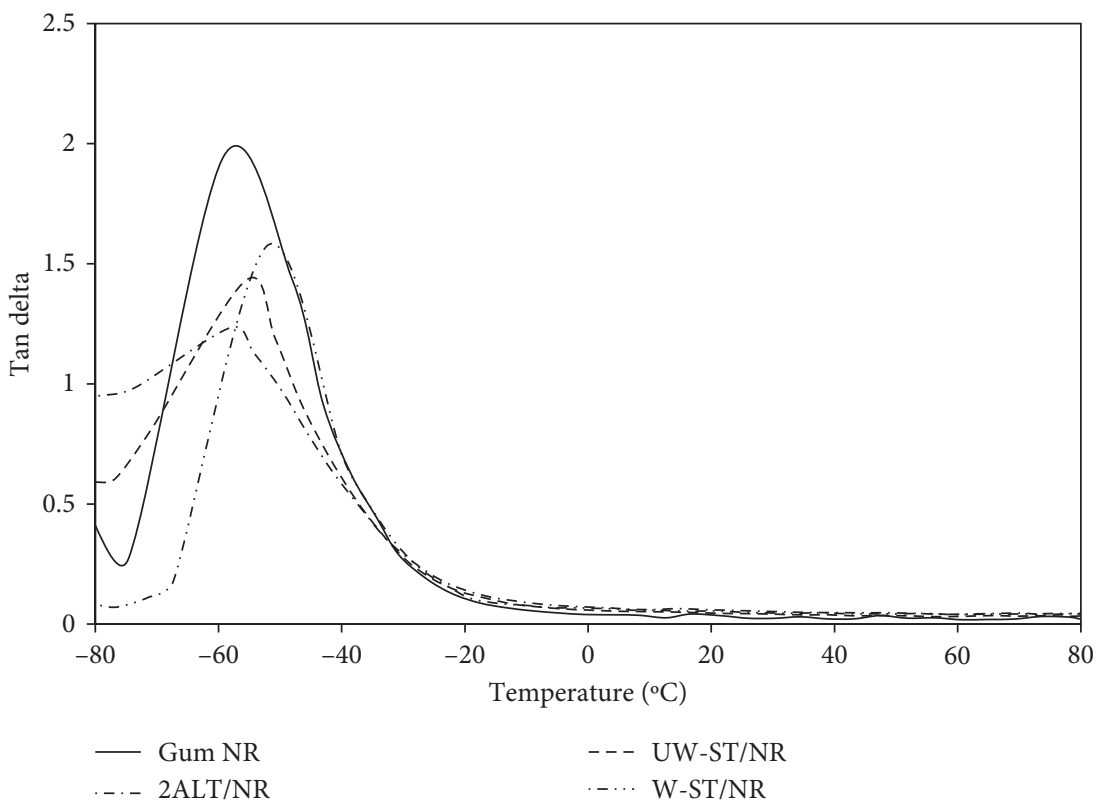

Figure 14: Tan $\delta$ of gum NR, 2ALT/NR, UW-ST/NR, and W-ST/NR composites.

NR composites was insignificantly different as compared with that of the gum NR. As temperature increased above the glassy region, the loss modulus of all NR composite specimens was higher than that of the gum NR. This was because the addition of RHF increased energy absorption in the system. In addition, the change in the loss modulus of NR composites was attributed to the filler-rubber interaction improvement after fiber surface treatment which decreased the mobility of rubber chains in the NR composites [32].
Tan $\delta$ values, as a function of temperature, of gum NR, $2 \mathrm{ALT} / \mathrm{NR}, \mathrm{UW}-\mathrm{ST} / \mathrm{NR}$, and W-ST/NR composites are illustrated in Figure 14. The peak temperature of $\tan \delta$ is used to identify the glass transition temperature $\left(T_{\mathrm{g}}\right)$ of a material [33]. From the figure, the $\tan \delta$ peak of all NR composites slightly shifted to higher temperatures as compared with that of the gum NR. Among the NR composites, the tan $\delta$ peak of the W-ST/NR composite appeared at the highest temperature. The increase in $\tan \delta$ or the increase in $T_{\mathrm{g}}$ of 
rubber composites indicated the improvement of filler-rubber interaction of the NR composites [33].

\section{Conclusions}

The RHF surface was treated with TESPT solution, a silane coupling agent with four sulphur atoms in its structure, using unwashing and washing treatment methods. The TESPT molecules deposited on the UW-ST and W-ST surfaces were confirmed by the appearance of $\mathrm{C}-\mathrm{H}$ stretching and $\mathrm{Si}-\mathrm{O}-\mathrm{Si}$ stretching of TESPT in the FTIR spectra of the treated RHF. In addition, the decrement of decomposition temperatures and the changes in the residue amounts of UW-ST and W-ST proved the removal of physisorbed silane layers after washing. Both UW-ST and W-ST affected cure characteristics, and mechanical, dynamic mechanical, and morphological properties of the NR composites. Scorch time and cure time of the W-ST/NR composite were longer than those of the UW-ST/NR composite. Furthermore, the incorporation of UW-ST and W-ST into NR enhanced M100, M300, tensile strength, elongation at break, tear strength, storage modulus, loss modulus, $\tan \delta$, and crosslink density of the NR composites. SEM micrographs of both UW-ST/NR and W-ST/NR composites also supported the mechanical and the dynamic mechanical property improvement of these two composites. The micrographs revealed that the RHF surfaces were covered with the NR matrix, which indicated the increase in filler-rubber interaction. According to the mechanical properties of the NR composites, the washing silane treatment method was more effective than the unwashing silane treatment method for compatibility improvement between RHF and NR. As compared with those of the 2ALT/NR composite, the modulus, tensile strength, and tear strength of the $\mathrm{W}$-ST/NR composite can be improved by $12 \%, 10 \%$, and $5 \%$, respectively, without deterioration of the elongation at break.

\section{Data Availability}

The data used to support the findings of this study are available from the corresponding author upon request.

\section{Conflicts of Interest}

The authors declare that there are no conflicts of interest regarding the publication of this paper.

\section{Acknowledgments}

The authors are grateful to the Suranaree University of Technology, the National Research Council of Thailand, and the Office of the Higher Education Commission (under the Higher Education Research Promotion and National Research University (NRU) Project of Thailand) for financial supports, Louis T. Leonowens (Thailand) Co., Ltd. for providing TESPT, and Channel Chemicals Co., Ltd. for providing rubber chemicals.

\section{References}

[1] M. Jacob, S. Thomas, and K. T. Varughese, "Mechanical properties of sisal/oil palm hybrid fiber reinforced natural rubber composites," Composites Science and Technology, vol. 64, no. 7-8, pp. 955-965, 2004.

[2] S. Panthapulakkal, A. Zereshkian, and M. Sain, "Preparation and characterization of wheat straw fibers for reinforcing application in injection molded thermoplastic composites," Bioresource Technology, vol. 97, no. 2, pp. 265$272,2006$.

[3] R. Nordin, C. M. S. Said, and H. Ismail, "Properties of rice husk powder/natural rubber composites," ECS Journal of Solid State Science and Technology, vol. 15, pp. 83-91, 2007.

[4] F. Martí-Ferrer, F. Vilaplana, A. Ribes-Greus et al., "Flour rice husk as filler in block copolymer polypropylene: effect of different coupling agents," Journal of Applied Polymer Science, vol. 99, no. 4, pp. 1823-1831, 2006.

[5] U. Huner, "Effect of chemical treatment and maleic anhydrided grafted polypropylene coupling agent on rice husk and rice husk composites," Materials Express, vol. 7, no. 2, pp. 134-144, 2017.

[6] F. P. De Carvalho, M. I. Felisberti, M. A. S. Oviedo et al., "Rice husk/poly(propylene-co-ethylene) composites: effect of different coupling agents on mechanical, thermal, and morphological properties," Journal of Applied Polymer Science, vol. 123, no. 6, pp. 3337-3344, 2012.

[7] H. D. Rozman, M. H. Lee, R. N. Kuma et al., "The effect of chemical modification of rice husk with glycidyl methacrylate on the mechanical and physical properties of rice huskpolystyrene composites," Journal of Wood Chemistry and Technology, vol. 20, no. 1, pp. 93-109, 2018.

[8] L. Yan, N. Chouw, and X. Yuan, "Improving the mechanical properties of natural fiber fabric reinforced epoxy composites by alkali treatment," Journal of Reinforced Plastics and Composites, vol. 31, no. 6, pp. 425-437, 2012.

[9] S. Thongsang and N. Sombatsompop, "Effect of $\mathrm{NaOH}$ and $\mathrm{Si69}$ treatments on the properties of fly ash/natural rubber composites," Polymer Composites, vol. 27, no. 1, pp. 30-40, 2006.

[10] H. Ismail, N. Othman, and M. Komethi, "Curing characteristics and mechanical properties of rattan powder filled natural rubber composites as a function of filler loading and silane coupling agent," Journal of Applied Polymer Science, vol. 123, no. 5, pp. 2805-2811, 2012.

[11] S. Chirachanchai, R. Chungchamroenkit, and H. Ishida, "Adsorption of tetrasulfide functional silane on high surface area silica treated with aqueous and non-aqueous solutions," Composite Interfaces, vol. 6, no. 2, pp. 155-167, 1998.

[12] T. Fukuda, S. Fujii, Y. Nakamura et al., "Mechanical properties of silica particle filled styrene butadiene rubber composites containing polysulfide type silane coupling agents: influence of loading method of silane," Journal of Applied Polymer Science, vol. 130, no. 1, pp. 322-329, 2013.

[13] T. Fukuda, S. Fujii, Y. Nakamura et al., "Tensile properties of styrene butadiene rubber/silica composites with mercapto functional silane coupling agents: influences of loading method and alkoxy group number," Composite Interfaces, vol. 20, no. 8, pp. 635-646, 2013.

[14] Y. Nakamura, H. Honda, A. Harada et al., "Mechanical properties of silane treated, silica-particle-filled polyisoprene rubber composites: effects of the loading amount and alkoxy group numbers of a silane coupling agent containing mercapto groups," Journal of Applied Polymer Science, vol. 113, no. 3, pp. 1507-1514, 2009. 
[15] L. Srisuwan, K. Jarukumjorn, and N. Suppakarn, "Properties of rice husk fiber/natural rubber composites: effect of rice husk fiber surface modification," in Proceedings of Pure and Applied Chemistry International Conference, pp. 1449-1452, Chiang Mai, Thailand, February 2012.

[16] L. Srisuwan, K. Jarukumjorn, and N. Suppakarn, "Effect of bis (triethoxysilylpropyl) tetrasulfide on physical properties of rice husk fiber/natural rubber composites," Advanced Materials Research, vol. 844, pp. 263-266, 2014.

[17] P. J. Flory, Principles of Polymer Chemistry, Cornell University Press, New York, NY, USA, 1953.

[18] K. Ahmed, S. Nizami, N. Raza et al., "Mechanical, swelling and thermal aging properties of marble sludge-natural rubber composites," International Journal of Industrial Chemistry, vol. 3, no. 1, pp. 1-12, 2012.

[19] L. Luduena, D. Fasce, V. A. Alvarez et al., "Nanocellulose from rice husk following alkaline treatment to remove silica," BioResources, vol. 4, pp. 1440-1453, 2011.

[20] S. D. Genieva, S. C. Turmanova, A. S. Dimitrova et al., "Characterization of rice husks and the products of its thermal degradation in air or nitrogen atmosphere," Journal of Thermal Analysis and Calorimetry, vol. 93, no. 2, pp. 387-396, 2008.

[21] M. M. Kabir, H. Wang, K. T. Lau et al., "Effects of chemical treatments on hemp fibre structure," Applied Surface Science, vol. 276, pp. 13-23, 2013.

[22] N. Lopattananon, D. Jitkalong, and M. Seadan, "Hybridized reinforcement of natural rubber with silane modified short cellulose fibers and silica," Journal of Applied Polymer Science, vol. 120, no. 6, pp. 3242-3254, 2011.

[23] T. H. Mokhothu, A. S. Luyt, and M. Messori, "Reinforcement of EPDM rubber with in situ generated silica particles in the presence of a coupling agent via a sol-gel route," Polymer Testing, vol. 33, pp. 97-106, 2014.

[24] W. Liu, A. K. Mohanty, L. T. Drzal et al., "Effects of alkali treatment on the structure, morphology and thermal properties of native grass fibers as reinforcements for polymer matrix composites," Journal of Materials Science, vol. 39, no. 3, pp. 1051-1054, 2004.

[25] Z. Zeng, W. Ren, C. Xu et al., "Effect of bis(3triethoxysilylpropyl) tetrasulfide on the crosslink structure, interfacial adhesion, and mechanical properties of natural rubber/cotton fiber composites," Journal of Applied Polymer Science, vol. 111, no. 1, pp. 437-443, 2009.

[26] H. Ismail, A. Rusli, and A. A. Rashid, "Maleated natural rubber as a coupling agent for paper sludge filled natural rubber composites," Polymer Testing, vol. 24, no. 7, pp. 856-862, 2005.

[27] K. Sahakaro and S. Beraheng, "Reinforcement of maleated natural rubber by precipitated silica," Journal of Applied Polymer Science, vol. 109, no. 6, pp. 3839-3848, 2008.

[28] B. T. Poh and C. C. Ng, "Effect of silane coupling agents on the mooney scorch time of silica-filled natural rubber compound," European Polymer Journal, vol. 34, no. 7, pp. 975979, 1998.

[29] P. Saramolee, P. Lertsuriwat, A. Hunyek et al., "Cure and mechanical properties of recycled NdFeB-natural rubber composites," Bulletin of Materials Science, vol. 33, no. 5, pp. 597-601, 2010.

[30] P. L. Teh, Z. A. M. Ishak, A. S. Hashim et al., "Effects of epoxidized natural rubber as a compatibilizer in melt compounded natural rubber-organoclay nanocomposites," $\mathrm{Eu}$ ropean Polymer Journal, vol. 40, no. 11, pp. 2513-2521, 2004.

[31] H. Ismail, N. Rosnah, and H. D. Rozman, "Curing characteristics and mechanical properties of short oil palm fibre reinforced rubber composites," Polymer, vol. 38, no. 16, pp. 4059-4064, 1997.

[32] W. Pongdong, C. Nakason, C. Kummerlowe et al., "Influence of filler from renewable resource and silane coupling agent on the properties of the epoxidized natural rubber vulcanizates," Journal of Chemistry, vol. 2015, Article ID 796459, 15 pages, 2015.

[33] N. Sombatsompop, "Dynamic mechanical properties of SBR and EPDM vulcanisates filled with cryogenically pulverized flexible polyurethane foam particles," Journal of Applied Polymer Science, vol. 74, no. 5, pp. 1129-1139, 1999. 


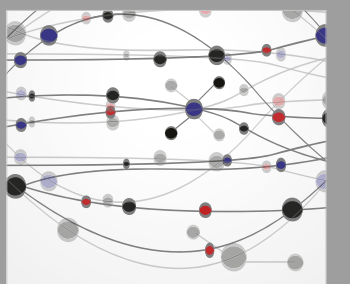

The Scientific World Journal
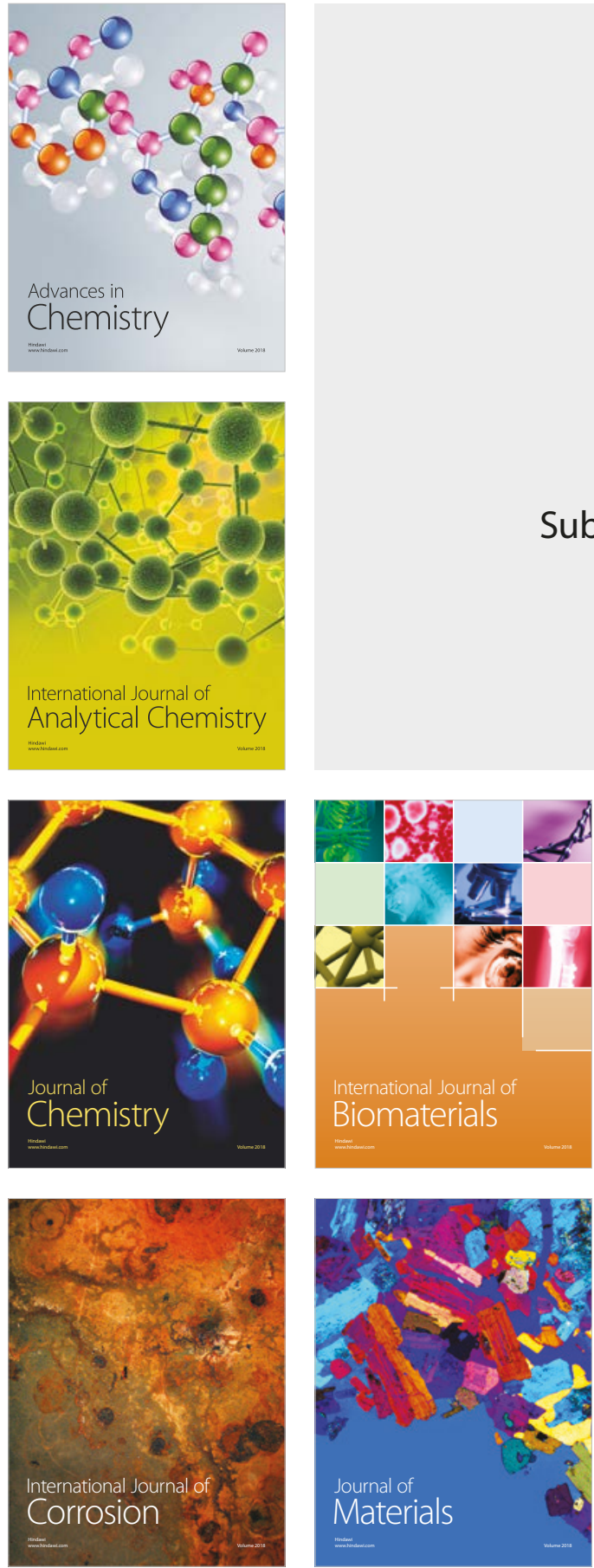

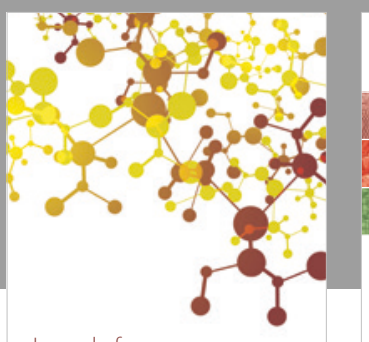

Journal of

Applied Chemistry
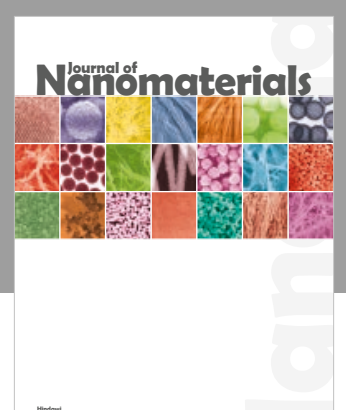

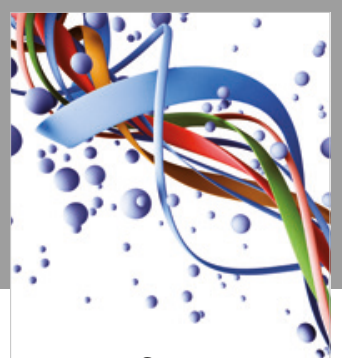

Scientifica

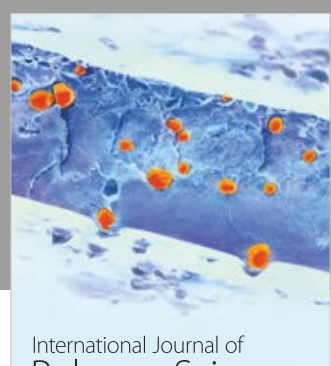

Polymer Science

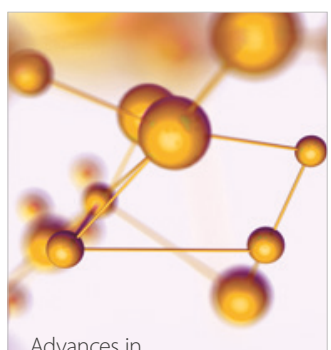

Physical Chemistry
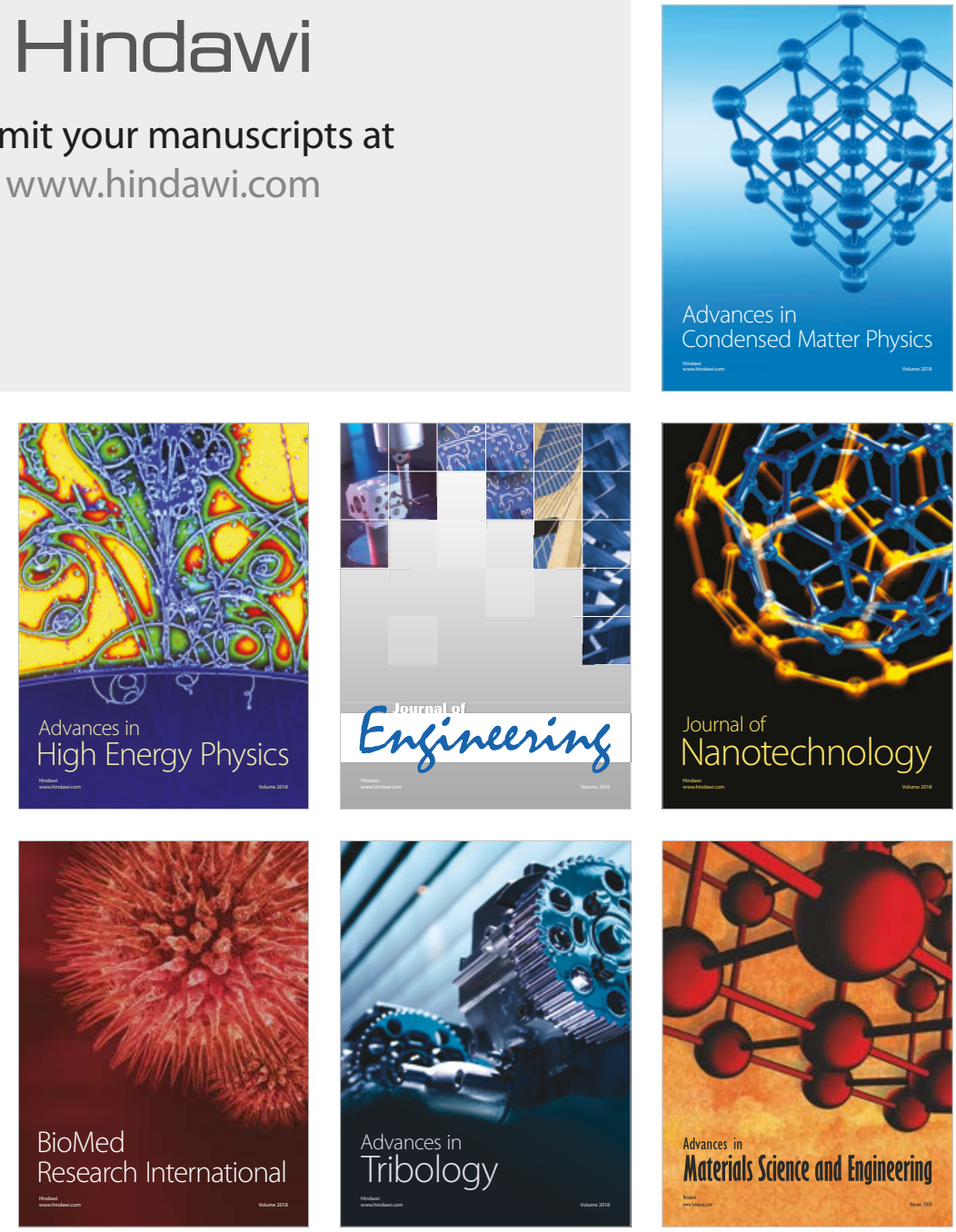